\title{
A RESPONSABILIDADE SOCIAL DO EMPREGADOR DURANTE A PANDEMIA
}

DA COVID-19

Alessandra de Andrade Barbosa Santos de Mesquita ${ }^{1}$

Evandro Afonso de Mesquita ${ }^{2}$

Recebido em 09/12/2020

Aceito em 20/12/2020

RESUMO: O Trabalho possui a finalidade de trazer a temática da Responsabilidade Social do Empregador, com a busca dos direitos sociais e fundamentais aliados ao Princípio da Fraternidade, princípio evidenciado no Preâmbulo da Constituição Federal/88. Uma manifestação para estímulo e concretização de conduta ética e consciente frente ao estado de calamidade pública decretado pelo Governo Federal, com foco nas consequências sobre o trabalhador, suas condições de trabalho, remuneração e segurança e saúde no trabalho. Uma indução necessária a uma nova visão sobre a empresa e os seus modos de funcionamento, uma visão mais ampla, com uma maior presença sobre a envolvente externa e questionamentos sobre quais os limites de ação da empresa. Por outro lado, trazer uma dimensão social e ética aos componentes de riqueza/lucro da empresa. O cenário global presente vem promovendo diversas remodelagens, mormente no Direito do Trabalho, após advento da COVID-19 que vem ameaçando a população mundial. O ordenamento jurídico brasileiro concebeu o direito à saúde como um direito social a partir da $\mathrm{CF} / 88$, impondo como direito de todos e dever do Estado além de políticas sociais e econômicas que visem à redução do risco de doença devendo dar essa garantia a todos os Cidadãos, tendo como o direito social que se encontram diretamente conectado ao princípio da dignidade e que é indispensável para uma vida saudável e digna. Busca-se no Princípio da Função Social da Empresa como um dos deveres fundamentais do empregador, com maior desempenho social perante a comunidade, dentre ela as entidades que exercem atividades empresariais.

PALAVRAS-CHAVE: Direitos Sociais. Fraternidade. Princípios Constitucionais. Continuidade da Relação de Emprego.COVID-19.

\section{EMPLOYER'S SOCIAL RESPONSIBILITY DURING THE COVID-19 PANDEMIC}

ABSTRACT: This paper has the purpose of the Work is to bring up the theme of Employer's Social Responsibility, with the search for social and fundamental rights allied to the Fraternity Principle, a principle brought by the Preamble of the Federal Constitution / 88. A demonstration for the encouragement and implementation of ethical and conscious

\footnotetext{
${ }^{1}$ Mestranda em Função Social do Direito pela faculdade FADISP-Faculdade Autônoma de Direito, Bolsista CAPES- Coordenação de Aperfeiçoamento de Pessoal de Nível Superior. Especialista Lato Sensu em Direito e Processo do Trabalho pela Universidade Mackenzie, Formada em Direito, em 2008, pela FARO - Faculdade de Rondônia. Advogada Trabalhista atuante desde 2012. Celular (11) 96180-1822 E-mail alessandraemesquitaadv@gmail.com. Modalidade artigo científico.

${ }^{2}$ Mestrando em Função Social do Direito pela faculdade FADISP-Faculdade Autônoma de Direito, Especialista Lato Sensu em Direito Público pela Universidade Federal de Rondônia - UNIR, Graduado em Direito, em 2008, pela Faculdade de Rondônia - FARO. Auditor-Fiscal do Trabalho. Celular (11) 98755-2925. E-mail evandroafonso@hotmail.com. Modalidade artigo científico.
} 
business conduct in the face of force majeure, focused on the company's workers, in the area of working conditions, employment, remuneration, health and hygiene. A necessary induction to a new view on the company and its modes of operation, a broader view, with a greater presence on the external environment and questions about the limits of the company's action. On the other hand, bring a social and ethical dimension to the company's wealth / profit components. The present global scenario has undergone several remodeling, especially in Labor Law, after the emergence of COVID-19, which has been threatening the world population. The Brazilian legal system conceived the right to health as a social right as of $\mathrm{CF} / 88$, making it possible as a right of all and a duty of the State and social and economic policies that aim to reduce the risk of disease and should give this guarantee to all Citizens, having as social rights that are directly connected to the principle of dignity and which is indispensable for a healthy and dignified life. The Social Function Principle of the company is sought as one of the fundamental duties of the employer, with greater social performance before the community, among them the entities that carry out business activitie

KEYWORDS: Social rights. Fraternity. Constitutional principles. Continuity of Employment Relationship.COVID-19

\section{INTRODUÇÃO}

O panorama atual vem promovendo diversas ressignificações, principalmente no Direito do Trabalho, após aparição do novo vírus que vem amedrontando a população mundial. O Comitê Internacional de Taxonomia de Vírus (ICTV) adotou "síndrome respiratória aguda grave 2 (SARSCoV-2)" como nome para o novo vírus causador da COVID-19.

Inicialmente, a doença foi identificada em Wuhan, na província de Hubei, República Popular da China . Muito rapidamente a doença se propagou por outros países em pouco tempo após o seu surgimento, a Organização Mundial da Saúde (OMS) classificou como uma pandemia mundial o surto do SARS-CoV-2, provocando diversas reações em todos os setores sociais e econômicos do mundo. Com advento desse cenário pandêmico, o Direito começou a se mover diante dos interesses dos cidadãos, a fim de que sejam respeitados e preservados os Direitos Sociais e suas Garantias Fundamentais, em especial, o direito à saúde, previstos nos artigos 196-198 da Constituição Federal de 1988 .

O ordenamento jurídico brasileiro compreendeu o direito à saúde como um direito social a partir da Constituição da República Federativa/88, impondo como direito de todos e dever do Estado, além de políticas sociais e econômicas que visem à redução do risco de doença, devendo dar essa garantia a todos os Cidadãos. O direito à saúde, como direito social, se encontra diretamente conectado ao princípio da dignidade e que é indispensável para uma vida digna e saudável.

Infere-se pelo Princípio da Função Social da empresa os deveres fundamentais do empregador, pois conforme a Constituição Federal de 1988 nos evidencia, o desempenho social 
perante à comunidade é aliado do Princípio da Fraternidade, este que pode ser encontrado em vários dispositivos constitucionais, se destacando dentre os direitos e garantias fundamentais , não apenas como uma hipótese ideal, mas como princípio ativo, orientador da conduta humana. $\mathrm{O}$ acolhimento dos direitos sociais não está ligado somente ao dever do Estado, mas sim de toda a sociedade, inserida aí as entidades que exercem atividades empresariais, nessa perspectiva que o presente artigo se estrutura.

Sendo assim, se faz necessário uma análise na posição da Doutrina e da CF/88, recorrendo às recomendações que vem sendo aplicadas com a finalidade de garantir e preservar os direitos sociais e fundamentais.

\section{A PANDEMIA DA COVID 19}

Em 31 de dezembro de 2019, a Organização Mundial da Saúde (OMS) foi alertada sobre vários casos de pneumonia na cidade de Wuhan, província de Hubei, na República Popular da China. Tratava-se de um novo tipo de coronavírus que não havia sido identificado antes em seres humanos, iniciou lá, naquela província, afetando aproximadamente 50 habitantes locais, principalmente, os que trabalhavam nas feiras de peixe e de venda de animais vivos.

Em pesquisas foram identificados sete coronavírus humanos (HCoVs): 1. HCoV-229E, 2. HCoV-3.OC43, 4.HCoV-NL63, 5.HCoV-HKU1, 6.SARS-COV (que causa síndrome respiratória aguda grave), 7.MERS-COV (síndrome respiratória do Oriente Médio - vírus causador) e o, mais recente, novo coronavírus (inicialmente fora nomeado 2019-nCoV e, em 11 de fevereiro de 2020, nomeado de SARS-CoV-2). Esse é o novo coronavírus e responsável por causar a doença COVID-19. Portanto esta denominação trata-se da doença, sendo o vírus transmissor nomeado como SARS-CoV2.

A OPAS (Organização Pan-Americana da Saúde) Brasil tem divulgado informações e dados sobre a COVID-19 e em 30 de janeiro de 2020 divulgou que a OMS (Organização Mundial de Saúde), em Genebra, Suíça, declarou que constitui Emergência de Saúde Pública de Importância Internacional (ESPII).

Afirmou o diretor-geral da OMS, Tedros Adhanom Ghebreyesus, que:

O principal motivo dessa declaração não diz respeito ao que está acontecendo na China, mas o que está acontecendo em outros países. Nossa maior preocupação é o potencial do vírus para se espalhar por países com sistemas de saúde mais fracos e mal preparados para lidar com ele. ${ }^{3}$

${ }^{3}$ OPAS. OMS declara emergência de saúde pública de importância internacional por surto de novo coronavírus. Publicado em 30/01/2020. Disponível em:

https://www.paho.org/bra/index.php?option=com_content\&view=article\&id=6100:oms-declara-emergencia-de-

Ponto de Vista Jurídico | Caçador | v.9 | nº 2 | p. 60 - 77 | jul./dez. 2020 
Trazendo esse cenário para o mundo do Direito do Trabalho, os líderes empresariais podem, senão afirmar que devem, direcionar parte do foco da empresa na saúde dos seus empregados e familiares e no controle/prevenção da COVID-19, cooperando ostensivamente, flexibilizando rotinas de trabalho e levando serviços e informações relevantes à sua força laboral.

O Pacto Global Brasil está liderando o tema com a seguinte abordagem:

Esta pandemia causada pelo coronavírus impactará fortemente a Agenda 2030.
Positivamente, já percebemos a redução das emissões de gases de efeito estufa. Por
outro lado, o contexto atual atinge diretamente a saúde da população e a
disponibilidade dos serviços médicos para atendimento a outras doenças. Além disso,
teremos que lutar contra o aumento da pobreza e da desigualdade social e a escassez
de recursos investidos em programas de sustentabilidade. Esperamos que esta crise
gere reflexão e uma mudança generalizada de comportamento para que o mundo,
mesmo com todas essas dificuldades, consiga atingir os ODS nesses 10 anos que
temos até 2030 . Como a maior iniciativa de sustentabilidade corporativa do mundo, o
Pacto Global está buscando mobilizar as empresas em ações de apoio neste momento
tão crítico da sociedade brasileira e mundial. ${ }^{4}$

No dia 24 de maio de 2020, no site ESTADÃO, foi divulgado, que no Brasil já apresentava mais de 363 mil infectados e 22,6 mil mortes pela COVID-19 e no dia 21 de setembro de 2020 já tinha alcançado, segundo aquele site : "Brasil: 126.230 mortes e 4.121.203 casos confirmados em todas as unidades federativas, de acordo com o Consórcio de Veículos de Imprensa.”, portanto esse cenário era e continua crítico, no qual se faz necessário o uso dos dispositivos constitucionais dos Direitos Sociais e Fundamentais para assegurar o direitos dos trabalhadores com respeito à dignidade da pessoa humana.

\section{DIREITOS SOCIAIS E DIREITOS FUNDAMENTAIS}

O preambulo da Constituição Federal/88 preconiza que “(...) a igualdade e a justiça como valores supremos de uma sociedade fraterna, pluralista e sem preconceitos, fundada na harmonia social e comprometida (...)" . Além dessa menção no seu preâmbulo, dispõe a aludida Constituição em seu artigo $3^{\circ}$, I, que constitui um dos objetivos fundamentais da República Federativa do Brasil, "construir uma sociedade livre, justa e solidária" e para tanto, deverá o Estado brasileiro, conforme incisos II, III e IV, do mesmo dispositivo, garantir o desenvolvimento nacional; erradicar a pobreza e a marginalização e reduzir as desigualdades sociais e regionais.

Os direitos sociais são assegurados na $\mathrm{CF} / 88$ que visa a proteção dos direitos da

saude-publica-de-importancia-internacional-em-relacao-a-novo-coronavirus\&Itemid=812 Acessado em: $16 / 09 / 2020$.

${ }^{4}$ PACTO GLOBAL REDE BRASIL Pacto contra a COVID-19. Disponível em: https://www.pactoglobal.org.br/pg/pacto-contra-covid-19 Acessado em: 21/09/2020. 
coletividade, mas também os direitos individuais, ambos considerados direitos fundamentais, que traz em seu artigo $6^{\circ}$, dentre os direitos sociais, o Direito ao Trabalho.

Igualmente o direito à saúde, como um direito social, deve ser também observado com atenção voltada à dignidade da pessoa humana e aliado aos princípios fundamentais, destacando que a proteção à pessoa humana deve ser a finalidade do Estado Democrático de Direito.

Para Alexandre de Moraes:

Direitos sociais são direitos fundamentais do homem, caracterizando-se como verdadeiras liberdades positivas, de observância obrigatória em um Estado Social de Direito, tendo por finalidade a melhoria de condições de vida aos hipossuficientes, visando a concretização da igualdade social, e são consagrados como fundamentos do Estado democrático, pelo Art. $1^{\circ}$, IV, da Constituição Federal.5

Como preceitua Wolfgang Sarlet, na previsão da Carta Magna/88, os direitos de terceira dimensão admitem os direitos de solidariedade e fraternidade que são desprendidos da figura do sujeito enquanto titular, destina-se ao abrigo de grupos humanos, caracterizando-se como direitos de titularidade coletiva ou difusa. Em meio aos mais citados direitos de terceira geração destaca-se o direito à paz, à autodeterminação dos povos, ao desenvolvimento, ao meio ambiente, à qualidade de vida e o direito de comunicação. Refere o autor que é inteligível a denominação usual de direitos de solidariedade ou de fraternidade devido "sua implicação universal ou, no mínimo, transindividual, e por exigirem esforços e responsabilidades em escala até mesmo mundial para sua efetivação"

Os direitos fundamentais para serem aplicados de forma regular, de maneira direta e frontal, nas relações jurídicas, ou como nas palavras de Gomes Canotilho, em que os direitos fundamentais "não são simples norma normarum mas norma normata", o que implica que devem ser aplicadas diretamente sobre os fatos sociais e não consideradas meras orientações programáticas. E Segundo Amauri Mascaro do Nascimento destaca a aplicação da Constituição para as relações de trabalho da seguinte forma:

\footnotetext{
A Constituição é aplicável ao empregado e aos demais trabalhadores nela expressamente indicados, e nos termos que o fez; ao rural, ao avulso, ao doméstico e ao servidor público. Não mencionando outros trabalhadores, como o eventual, o autônomo e o temporário, os direitos destes ficam dependentes de alterações da lei ordinária, à qual se restringem. ${ }^{6}$
}

Dentre os Princípios norteadores do Direito do Trabalho trazemos à baila alguns que são determinantes para a relação de emprego, tais como os Princípios da Irrenunciabilidade da Direitos, Indisponibilidade de Direitos, Continuidade da Relação de Emprego, Inalterabilidade Contratual.

${ }^{5}$ MORAES, Alexandre de. Direito Constitucional. 25 Ed. São Paulo, Atlas. 2010. p.197.

${ }^{6}$ NASCIMENTO, Amauri Mascaro. Direito do Trabalho na Constituição de 1988. São Paulo, Saraiva, 1989.p.34. 
Ricardo Pereira de Freitas Guimarães esclarece que o Princípio de Continuidade da Relação de emprego, da seguinte forma: "O contrato de trabalho tem como regra sua indeterminação, tanto é verdade, que a própria legislação enumera as hipóteses em que referidos contratos podem ser firmados por prazo determinado (...)”. . Por outro lado, o Autor também destaca:

Contudo, o princípio da continuidade da empresa ou da preservação da empresa é princípio que volta os olhos à própria empresa, reconhecendo sua função social e a importância da sua manutenção e existência no mundo jurídico, pois, afinal, sem empregadores, não teremos empregados, portanto nada mais razoável. ${ }^{7}$

Nesse período, que se atravessa com grandes e inúmeras dificuldades empresariais, se faz necessário lançar mão, fazendo uso do bom senso, dos dispositivos e princípios que norteiam as relações de trabalho.

\section{A COVID-19 E APLICAÇÃO DO "FATO DO PRÍNCIPE"}

O distanciamento social ainda é a principal medida para proteger da contaminação do coronavírus e o site UOL destacou:

As quarentenas e restrições decretadas por diferentes estados e municípios do Brasil por conta da propagação do novo coronavírus não podem impedir, em tese, que alguém faça uma viagem dentro do país ou saia de casa para dar uma volta no quarteirão. ${ }^{8}$

Por conta da COVID-19, estados e municípios adotaram medidas restritivas tentando buscar o maior percentual de confinamento possível, de forma que as medidas por muitas vezes foram exaustivamente questionadas, mas cada uma no objetivo de diminuir o maior número possível de infectados. Contudo já se passaram meses, dessas medidas, e ainda no mês de setembro de 2020, na maioria dos Estados brasileiros não retornaram as aulas presenciais nas instituições de ensino, ou seja, muitos profissionais que atuam na área da Educação estão fora do mercado de trabalho, pois é sabido que, além dos Professores, é necessário vários outros cargos/funções que fazem a Instituição de Ensino funcionar.

No cenário que observamos nos últimos meses, com a decretação da paralisação em diversos serviços (escolas, comércios, shoppings, dentre outros) em muitos Estados, para se cumprir o maior índice possível de distanciamento social, vem de uma preocupação com a saúde pública e da recomendação da Organização Mundial de Saúde, a fim de evitar que a COVID-19 seja alastrada pela

\footnotetext{
${ }^{7}$ Idem. p. 96.

${ }^{8}$ UOL. Quarentena em São Paulo e no Rio: O que você pode e o que não pode fazer. Publicado em 25/03/2020. Disponível em: https://noticias.uol.com.br/saude/ultimas-noticias/redacao/2020/03/25/quarentena-em-sao-pauloo-que-voce-pode-e-o-que-nao-pode-fazer.htm Acessado em 21/09/2020.
} 
população. O distanciamento social ainda é a melhor medida para evitar a contaminação SARS-CoV2 que causa a doença COVID-19, mas o Estado não pode impedir que as pessoas saiam de casa, conforme previsto no art. 5, inc. XV da Constituição Federal de 88 , apenas pode agir por meio de orientações e restrições.

Frente a esse crítico cenário muito se fala das relações trabalhistas e na responsabilidade trabalhista do empregador, independente de mudanças drásticas externas, explana Maurício Godinho Delgado:

\begin{abstract}
É que este ramo jurídico especializado coloca sob ônus do empregador os riscos do empreendimento (art. $2^{\circ}$, caput, CLT), independentemente do insucesso que possa se abater sobre este. As obrigações trabalhistas empresariais preservam-se intocadas ainda que a atividade econômica tenha sofrido revezes efetivos em virtude de fatos externos à atuação do empregador. Fatores relevantes como a crise econômica geral ou a crise específica de certo segmento, mudanças drásticas na política industrial do Estado ou em sua política cambial - fatores que, obviamente, afetam a atividade da empresa - não são acolhidos como excludentes ou atenuantes da responsabilidade trabalhista do empregador. A esse propósito, aliás, a jurisprudência tem reiteradamente esclarecido que no conceito de riscos assumidos pelo empregador inscreve-se, sim, a profusão legislativa que sempre caracterizou a tradição jurídica e administrativa brasileira, com as modificações econômicas e monetárias daí advindas (Plano Bresser, Plano Verão, Plano Collor, Plano Real, etc.). Portanto, prejuízos derivados de tais planos econômicos oficiais não eliminam ou restringem a responsabilidade do empregador por suas obrigações laborativas. ${ }^{9}$
\end{abstract}

Em uma decisão proferida no dia 30 de abril de 2020, a juíza da $3^{\text {a }}$ Vara do Trabalho de Salvador, determinou, no processo sob o n. 0000212-51.2020.5.05.0003, a reintegração de 10 funcionários demitidos com base na Teoria do Fato do Príncipe, em sua decisão esclarece:

Trata-se de premissa axiológica de manutenção de emprego digno e das próprias condições de vida, alimentação e saúde do trabalhador e da sua família, mediante suspensão contratual que não onerará excessivamente o empregador, pois a MP prevê que os custos salariais ficarão a cargo do Poder Público. ${ }^{10}$

Na decisão supramencionada a empresa mesmo tendo o socorro das medidas do governo, mas precisamente da MP 936/20 que institui o Programa Emergencial de Manutenção do Emprego e da Renda , achou por bem desligar 10 de seus empregados e deixá-los a mercê da nova categoria de “desempregados da COVID-19".

A utilização da boa-fé por muitas vezes é escassa e no que tange o assunto Responsabilidade Social, Judith Martins Costa afirma sobre a rara jurisprudência trabalhista sobre esse tema:

A jurisprudência trabalhista acerca da boa-fé é escassa. A possibilidade de uma

\footnotetext{
${ }^{9}$ DELGADO, Maurício Godinho. Curso de Direito do Trabalho. $16^{\mathrm{a}}$ Ed. São Paulo, LTr. p.2019

${ }^{10}$ CONJUR. Juiz ordena reintegração de funcionários demitidos com base no fato do príncipe. Disponível em https://www.conjur.com.br/dl/juiz-ordena-reintegracao-funcionarios.pdf Acessado em: 18/09/2020.
} 
construção racionalmente ajustada e racionalmente controlável do princípio da boa-fé é dificultosa, pois a expressão é conotada a vários outros institutos. $\mathrm{O}$ apelo à boa-fé é por vezes utilizado em casos de «danos morais», essa vasta, hoje indistinta e praticamente incontrolável categoria jurídica que a tudo pretende acomodar, no mais das vezes com base em critérios irracionais, como os sentimentos, ou incompatíveis com o próprio sistema constitucional, como o do dano social. ${ }^{11}$

A teoria do fato do príncipe, está prevista no artigo 486 da CLT, este dispositivo permite que em situações excepcionais, quando há prejuízo financeiro desproporcional à empresa, decorrente de medidas adotadas pelas autoridades municipal, estadual ou federal, ou pela promulgação de lei ou resolução, o empregador poderá rescindir contratos e os custos oriundos dessa prática ficarão a cargo da autoridade envolvida. Mozart Victor Russomano já declarava que o "factum principis é ato de autoridade pública que determina a suspensão temporária ou definitiva das atividades da empresa, evidentemente, na forma da definição do art. 501 e ss., é modalidade de força maior”"

Tratando-se de vidas que estão sendo expostas ao SARS-CoV-2, vírus transmissor da COVID-19, as medidas de motivação ao confinamento se tornam eficazes e não por uma vontade exclusiva dos chefes de governo, mas por uma decisão forçosa em virtude da pandemia, portanto a aplicação do Fato do Príncipe nesse cenário não seria uma medida adequada e muito menos "honesta", pois essas restrições são fundamentadas na preservação da espécie humana. , e, inclusive, o risco da atividade econômica é do próprio empregador, conforme previsão legal prevista no art. $2, \S 2^{\circ} \mathrm{da}$ CLT e no art. 170, III da CF, não podendo repassar a um terceiro essa responsabilidade.

O site "Diário do Rio" noticia sobre atitude da grande e conhecida Rede de Churrascarias "Fogo de Chão" com a seguinte chamada: "Alegando ser forçado pelas consequências da pandemia do novo coronavírus, o famoso restaurante de carnes demitiu nada menos que 690 funcionários no mês de abril." Na matéria veiculada esclarece que a empregador se socorre à teoria do Fato do Príncipe demitindo parte de seus empregados e mandando a conta para os Governadores pagarem.

Um dia antes do noticiado acima, a rede de pizzaria Parmê usou do mesmo recurso para resilir os contratos com seus empregados:

(...) a Parmê, rede de pizzarias com mais de 30 lojas espalhadas pela cidade. Segundo relatos de funcionários demitidos, a empresa os dispensou e não pagou todas as verbas rescisórias, argumentando, para tal, que estaria amparada pela lei e que o governo arcaria com o que ficou restando. Ainda segundo os ex-funcionários, teriam sido nada menos que 579 empregados demitidos

(...). De acordo com a advogada Juliana Bracks, especialista em assuntos trabalhistas, a CLT possui um artigo que diz que ficará a cargo do governo pagar as indenizações caso seja comprovado que a referida empresa demitiu os funcionários devido a "força maior", por conta de "ato de autoridade municipal, estadual ou federal, ou pela

\footnotetext{
${ }^{11}$ COSTA, Judith Martins. A boa-fé no Direito Privado - critérios para a sua aplicação. $2^{\mathrm{a}}$ ed. São Paulo, Saraiva Educação, e-book, 2018. p.214
} 
promulgação de lei ou resolução que impossibilite a continuação da atividade". ${ }^{12}$

Para Ricardo Calcini, colunista da CONJUR, em 23 de maio de 2020, esclarecia que o Fato do Príncipe previsto na $\mathrm{CLT}^{13}$, que o dispositivo em questão só é valido quando gera a completa impossibilidade de execução do contrato de trabalho, explica:

Assim, a paralisação temporária ou definitiva do trabalho, por ato de autoridade municipal, estadual ou federal, deve acarretar, necessariamente, na impossibilidade de continuação da atividade empresarial. Somente nesta situação, caso seja comprovada, é que indenização do FGTS ficará a cargo governo responsável. ${ }^{14}$

O Ministério Público do Trabalho do Rio de Janeiro/RJ, no dia 25/05/2020, requereu, por meio de ACP - Ação Civil Pública, a nulidade das rescisões contratuais dos empregados da Rede de Churrascarias "Fogo de Chão", previsto no artigo 486 da CLT e mais a condenação dessa empresa ao pagamento de 70 milhões de reais com o objetivo de indenizar os danos morais coletivos. Contudo, após decorrido 2 (dois) dias, a Churrascaria reconsiderou sua estratégia de avocar "O Fato do Príncipe" com base no artigo da 486 da CLT , no qual aceitou pagar as verbas rescisórias dos empregados em sua integralidade, justificando-se que "as questões jurídicas levantadas e o impacto financeiro desta solução para os membros das equipes e suas famílias"

O Governo Federal através da Medida Provisória n. 936 trouxe algumas opções para o Empregador, podendo inclusive, ser o Empregador Doméstico, evitar a rescisão contratual com base no artigo 486 da CLT, portanto um socorro para que as Empresas possam exercer sua Responsabilidade Social e respeitar a dignidade da pessoa humana.

\section{RESPONSABILIDADE SOCIAL}

O mundo dos dias atuais, pós pandemia da COVID-19, vem passando por diversas transformações na economia, política, bem como no ambiente social e cultural, que vem forçando uma mudança na forma como as instituições se relacionam entre si e com a sociedade e é crescente o público consumerista que se veste de preocupações sociais e, principalmente, com o meio ambiente, muitas vezes sendo fator decisório no ato de consumir . Portanto, a Responsabilidade Social vem se tornando cada vez mais um elemento para tomada de decisão para a sobrevivência dos negócios, produtos e serviços, nisso envolve diretamente o mundo das empresas.

Nesse cenário, os estudos começaram a ganhar importância nos que se relacionam à

\footnotetext{
${ }^{12}$ DIÁRIO DO RIO. Parmê demite funcionários e diz que governo pagará verbas rescisórias. Publicado em 30/05/2020. Disponível em https://diariodorio.com/parme-demite-funcionarios-e-diz-que-governo-pagara-verbasrescisorias/ Acessado em 18/09/2020.

${ }^{13}$ Ibidem página 8.

${ }^{14}$ CONSULTOR JURÍDICO. Fato do príncipe não deve prosperar como argumento para governo pagar indenizações. Publicado em 24 de maio de 2020. Disponível em: https://www.conjur.com.br/2020-mai-23/fatoprincipe-nao-prosperar-argumento-justica-trabalho Acessado em: 22/09/2020.
} 
Responsabilidade Social, tendo esse estudo iniciado na década de 50 nos Estados Unidos e na década seguinte na Europa .

De acordo com o Livro Verde da Comissão Europeia (2001), orienta a conceituação da Responsabilidade Social empresarial:

\begin{abstract}
Ao afirmarem a sua responsabilidade social e assumirem voluntariamente compromissos que vão para além dos requisitos reguladores convencionais a que, de qualquer forma, estariam sempre vinculadas, as empresas procuram elevar o grau de exigência das normas relacionadas com o desenvolvimento social, a protecção ambiental e o respeito dos direitos fundamentais e adoptam uma governação aberta em que se conciliam os interesses de diversas partes, numa abordagem global da qualidade e do desenvolvimento sustentável. Embora se reconheça a importância de todos estes aspectos, o presente documento centra-se fundamentalmente nas responsabilidades das empresas em termos sociais. ${ }^{15}$
\end{abstract}

Para Carlos Cabral Cardoso temos dois níveis de Responsabilidade Social, o primeiro o nível interno, relacionado aos trabalhadores e demais partes diretamente interessadas e afetadas pelas decisões da companhia, e o segundo o nível externo que considera as consequências das referidas decisões em relação ao ambiente em que está inserido, seus parceiros e sociedade em geral. ${ }^{16}$

Por outra seara não devemos esquecer que as empresas, principalmente a grandes empresas, devem se imbuir da Responsabilidade Social para com seus empregados, buscando amenizar a situação imposta e usar os recursos disponibilizados pelos governos estaduais e federais. A Responsabilidade Social deve ser apoiada no Princípio da Proteção em que se define que o empregado é a parte mais fraca da relação contratual. Imaginemos, na verdade vemos todos os dias nas mídias ${ }^{17}$, que de uma hora para outra muitos trabalhadores, chefes de família, deixam de receber seus benefícios, salários e perdem a perspectiva de um futuro, uma nova classe de desempregados se forma, a Classe dos desempregados vítimas da Pandemia da COVID-19 ${ }^{18}$.

Para construirmos uma base sólida de Responsabilidade Social do Empregador se faz necessário trazer à baila o Princípio da Fraternidade, como definido nas palavras do Ministro do STJ, Reynaldo Fonseca:

Toda via autocompositiva decorre do princípio da fraternidade. Precisamos resgatar

\footnotetext{
15 LIVRO VERDE, 2001. Promover um quadro europeu para a responsabilidade social das empresas. Disponível em: https:/eur-lex.europa.eu/legal-content/PT/TXT/HTML/?uri=CELEX:52001DC0366\&from=SV Acessado em: 21/09/2020.

${ }^{16}$ CARDOSO, Carlos Cabral. Ética e Responsabilidade Social. Comportamento Organizacional e Gestão 21 temas e debates para o século XXI. Lisboa/Portugal. 2002.

${ }^{17}$ AGÊNCIA BRASIL. Governo estima em 150 mil número de desempregados em razão da pandemia. Publicado em 02/03/2020. Disponível em: https://agenciabrasil.ebc.com.br/economia/noticia/2020-04/governo-estima-em150-mil-os-desempregados-por-causa-da-pandemia Acessado em: 18/09/2020

${ }^{18}$ Ibidem página 9.
} 
esse princípio esquecido para que seja incorporado cada dia mais no nosso ordenamento jurídico, assim como foram a liberdade e a igualdade. Não fomos acostumados a construir soluções pacíficas. Somos acostumados a substituir a vontade das partes pela a do Estado. Hoje são 108 milhões de processos na Justiça Brasileira. Não há como responder a todos esses casos senão pela via autocompositiva ${ }^{19}$

As grandes empresas conseguem se manter economicamente por um tempo, outras fecham as portas , portanto aquelas com base na Responsabilidade Social que tanto falam, podem buscar alternativas para que resguarde o direito à dignidade (da pessoa humana) de seus empregados, sobretudo o da subsistência deles e de suas famílias. A MP 936 traz o Programa Emergencial de Manutenção do Emprego e da Renda para assegura esse mínimo de subsistência. No artigo $2^{\circ}$ da Medida Provisória aborda o seguinte “(...) III - reduzir o impacto social decorrente das consequências do estado de calamidade pública e de emergência de saúde pública.”.

Para Vólia Bomfim Cassar "A responsabilidade social da empresa deve partir de uma postura voluntária do empresário, enquanto a função social da empresa, por ser norma cogente, constitucional, deve ser de observância obrigatória" ., portanto para uma sociedade mais justa, sua responsabilidade, está diretamente ligada aos seus empregados.

Para André Ramos Tavares que o direito econômico das empresas tem associação social Constitucional:

\begin{abstract}
Em todas as discussões, foi destacado o caráter econômico do âmbito empresarial, e, ademais, a maneira pela qual esta faceta de caráter privado encontra uma contrapartida de cunho coletivo ou social em quase todos os preceitos constitucionais. Nesse sentido, da mesma forma que os princípios de direito econômico ligados à atividade empresarial encontram suas contrapartidas sociais no regime constitucional brasileiro, não é diferente com a previsão de deveres constitucionais, de caráter social, postulados que se erigem em contrapartida aos direitos e prerrogativas de cariz privado do setor empresário. ${ }^{20}$
\end{abstract}

O fato é que a Responsabilidade Social passou a ser vista como um diferencial relevante e diversas empresas estão cada vez mais dispostas a complementar sua imagem com esse elemento. De acordo com o fundador e presidente do Instituto Ethos, Oded Grajew, destacou-se no cenário empresarial brasileiro como um importante disseminador de ideias ligadas à Responsabilidade Social Empresarial:

Hoje, no entanto, existe um entendimento do conceito de responsabilidade social que já foi assimilado pelas empresas. A relação com a comunidade, até por motivos históricos e peculiaridades à realidade social brasileira, está mais evoluída. O que falta para muitas empresas é assumir a responsabilidade social como visão estratégica de negócios, comandada pelo principal executivo e utilizando instrumentos de gestão que

\footnotetext{
${ }^{19}$ TJDFT. Parceria entre VIJ/DF e IEDF resgata o princípio da fraternidade para beneficiar crianças e adolescentes do DF. Disponível em: https://www.tjdft.jus.br/informacoes/infancia-e-juventude/noticias-edestaques/2017/agosto/parceria-entre-vij-df-e-iedf-resgata-o-principio-da-fraternidade-para-beneficiar-criancase-adolescentes-do-df Acessado em: 20/08/2020
}

${ }^{20}$ TAVARES, André Barros. Direito Constitucional da Empresa. São Paulo, Método, 2013. p.93. 
possam mensurar, planejar e avaliar o estágio de responsabilidade social na empresa. ${ }^{21}$

Trata-se, portanto, de "um dos mais novos e importantes pilares da arquitetura econômica global” e, de acordo com a Organização para Cooperação e Desenvolvimento Econômico (OCDE), grupo das trinta mais avançadas economias industriais do mundo, "a governança corporativa é um dos instrumentos determinantes do desenvolvimento sustentável, em suas três dimensões - a econômica, a ambiental e a social”. Apesar dessa reconhecida importância na gestão e desenvolvimento do crescimento econômico, a governança corporativa, apesar de largamente difundida, ainda não está internalizada de fato pelo meio corporativo.

Isso ocorre pelo fato de que o assunto ainda ser relativamente novo, pela sua abrangência e possibilidade de ser abordada sob diversos aspectos (legal, financeira, estratégica, gestão) e pela diversidade de modelos existentes.

A igualdade material, outrossim, é a forma mais legítima de se conseguir a justiça em um Estado que se propõe a ser chamado de Estado de Direito, é inadmissível que grupos desfavorecidos social, econômico ou historicamente não tenham as mesmas condições dos demais. É dever do Estado a inclusão social daqueles que são marginalizados.

\section{RESPONSABILIDADE SOCIAL DO EMPREGADOR}

Encontra-se uma necessidade de se recorrer à Responsabilidade Social do Empregador, fazendo uma busca no texto Constitucional, nos seus Direitos Sociais, Fundamentais e principalmente nos princípios que regem a proteção do trabalhador. Os autores Fabrício Lima Silva e Iuri Pinheiro abordam sobre o tema da Governança Corporativa como "A governança corporativa possui como princípios fundamentais: i) transparência (disclosure); ii) equidade (fairness); iii) prestação de contas (accountability); e, iv) conformidade (compliance).”, a expressão conformidade está ligado ao dever de estar de acordo com as normas jurídicas e regulamento interno da empresa, e aqui especificamente os que regem os contratos laborais.

Para Fábio Nusdeo, na obra “Curso de Economia”, esclarece o seguinte:

Com efeito, quanto a este aspecto, limitavam-se estes últimos lastrear as suas teorias no modelo paupérrimo de autonomia dos agentes econômicos, autorregulados pelo mercado, caracterizado este pelos seus três pilares fundamentais: a propriedade privada com nítida e ampla definição dos direitos de propriedade sobre cada bem, a liberdade de contrato, e a responsabilidade patrimonial dos agentes econômicos pelas obrigações contratualmente assumidas, sem aventar ou examinar as

\footnotetext{
${ }^{21}$ FGV - SB. Sistema de Bibliotecas. GV Executivo. Entrevista Oded Grajew. Disponível em: http://bibliotecadigital.fgv.br/ojs/index.php/gvexecutivo/article/view/34544 Acessado em: 21/09/2020.
} 
condicionantes institucionais prevalecentes em cada segmento do mercado. ${ }^{22}$

As organizações socialmente responsáveis são aquelas que repensam suas posturas, comportamentos e condutas atuais e, dessa forma, se estruturam para colocar em prática atitudes que promovam o bem-estar dos envolvidos. Segundo o site da FIA define Responsabilidade Social como "Responsabilidade social (RS) é um conceito que engloba as ações voluntárias de empresas que atuam em benefício do seu público, tanto interno quanto externo." Ainda define as Responsabilidades Sociais como: "Responsabilidade Social Corporativa (RSC), Responsabilidade Social Empresarial (RSE) e Responsabilidade Social Ambiental (RSA)"

Recorremos ao site "Rockcontent" que faz uma conceituação objetiva sobre Responsabilidade Social e nos aclara:

A responsabilidade social empresarial também é conhecida como conscientização corporativa ou cidadania empresarial, sendo que a escolha do nome costuma levar em consideração o que pode ser melhor para passar o conceito a colaboradores, parceiros e clientes. ${ }^{23}$

Fábio Nusdeo nos orienta sobre a Responsabilidade Social do empregador

O Welfare State - Nas nações maduras, os Estados têm agido primordialmente no campo do bem estar social, conhecido como Welfare State. Este nada mais vem a ser do que um conjunto de instituições cujo objetivo é assegurar aos cidadãos um mínimo de atendimento às necessidades, particularmente no campo da saúde e saneamento, da educação e cultura, da seguridade social e, consequentemente, na orientação do aparelho produtivo à geração dos bens e serviços correspondentes. Integram o quadro institutos tais como o do seguro desemprego e os chamados programas de renda mínima, onde se inclui o conceito de imposto de renda negativo, ou seja, ao invés de pagar, aquele que recebe abaixo de um nível mínimo faz jus a uma compensação. Naturalmente todos esses programas são custeados por uma tributação diferenciada, a fim de captar os recursos de forma racional e sem gerar outros tipos de desigualdades ou distorções. ${ }^{24}$

Daí, o papel fundamental do Estado no papel de gestor, apoiando o Empregador para que exerça sua Responsabilidade Social, que muito bem caracterizada com a manutenção da relação de emprego com apoio a Medida Provisória n.936/2020 . Em meio a essa Pandemia que não só atinge a economia do Brasil, mas também grande parte do mundo, temos que harmonizar às decisões usando

\footnotetext{
${ }^{22}$ NUSDEO, Fábio. Curso de Economia. Introdução ao direito econômico. $9^{\text {a }}$ ed-ebook. São Paulo, Revista dos Tribunais, 2015.p.455.460.

${ }^{23}$ ROCKCONTENT. A Responsabilidade Social Empresarial é uma política que guia todos os passos da empresa, de forma a torná-la mais ética, responsável, sustentável e humana. A RSE influencia na condução do negócio e como a empresa lida com os parceiros, colaboradores e clientes. Publicado em 10/09/2019. Disponível em: https://rockcontent.com/blog/responsabilidade-social-empresarial/ Acessado em: 21/09/2020.

${ }^{24}$ NUSDEO, Fábio. Curso de Economia. Introdução ao direito econômico. $9^{\text {a }}$ ed-ebook. São Paulo, Revista dos Tribunais, 2015. p.221.
} 
corretamente as normas jurídicas minimizar os impactos nas relações de trabalho.

No Brasil mais R 5 bilhões em doações, não só das grandes empresas, mas também de pessoas físicas , ademais a Responsabilidade Social é um sentimento cívico solidário, que deve ser muito além de uma obrigação.

\section{CONCLUSÕES}

Não sobeja dúvida que a pandemia do coronavírus pode ser qualificada como força maior, uma força da natureza, se assim podemos afirmar, mas que se espalhou pelo mundo rapidamente e certamente afetará as relações jurídicas por onde quer que tenha se propagado. Dado todo o explanado até então, percebe-se que a pandemia do SARS-CoV-2 mudou e continua mudando as relações de trabalho e a vida de todas as pessoas e dos seus governantes, trazendo às empresas um grande sentimento de Responsabilização Social que vai além da jurídica. Por outro lado, podendo a empresa arcar ou não com os custos dessa fase de "portas fechadas", ou seja, níveis baixos de produção ou produção quase zero, seguramente provocará inúmeras novas relações jurídicas e de pleitos judiciais e/ou administrativas, pois numerosos direitos serão atingidos, independentemente da situação em que se encontre a economia do País e do Empregador.

Consequentemente muitos direitos serão negligenciados, pois como expõe Ilnah Toledo Augusto a ideia de acesso à justiça social não é universal, não abrangendo todos os grupos sociais presentes no meio urbano, em que os que possuem recursos para patrocinar os melhores advogados conseguem ter um acesso mais ágil e eficaz nas demandas judiciais.

Não temos como fazer uma previsão de quando haverá o retorno à normalidade das atividades empresariais e não se sabe se, uma vez retomada a normalidade, se não haverá necessidade de novas restrições de locomoção e determinação de suspensão de várias frentes de trabalho, portanto deve haver um consenso da importância das prevalência dos Direitos Sociais e Fundamentais, neles inserido o Princípio da Fraternidade, como uma prática que deve ser por todos imbuída, de forma a movimentar o sistema de produção e o de subsistência dos que dele dependem.

Que a Sociedade como um todo tenha plena ciência dos recursos disponíveis no nosso ordenamento jurídico e social, o fluxo contínuo que interliga numa razão de causa e efeito a Constituição Federal como irradiador da dignidade da pessoa humana, dos direitos sociais, fundamentais e o Princípio da Fraternidade, para a Responsabilidade Social da empresa e do próprio Estado.

Que essa experiência, que deixará marcas profundas no mundo, difunda ainda mais o senso de Responsabilidade Social do Empregador, promovendo a interação entre a iniciativa privada 
e a sociedade, e que faça crescer para um novo e superior estágio, na busca da consolidação de uma Sociedade mais justa, solidária e fraterna.

\section{REFERENCIAS BIBLIOGRAFICAS}

AGÊNCIA BRASIL. Governo estima em 150 mil número de desempregados em razão da pandemia. Publicado em 02/03/2020. Disponível em:

https://agenciabrasil.ebc.com.br/economia/noticia/2020-04/governo-estima-em-150-mil-osdesempregados-por-causa-da-pandemia Acessado em: 18/09/2020

AGÊNCIA BRASIL. Covid- 19: maioria dos estados segue sem aulas presenciais. Publicado e atualizado em 21/09/2020. Disponível em:

https://agenciabrasil.ebc.com.br/economia/noticia/2020-09/covid-maioria-dos-estados-seguesem-aulas-presenciais Acessado em: 21/09/2020

AGÊNCIA CMA. OMS mantém recomendação de distanciamento social para conter pandemia. Publicado em 30/03/2020. Disponível em: https://www.agenciacma.com.br/omsmantem-recomendacao-de-distanciamento-social-para-conter-pandemia/ Acessado em: 21/09/2020.

AGENDA FIOCRUZ DE NOTÍCIA. Radis aborda preparo do SUS contra o novo coronavírus. Publicado em 02/03/2020. Disponível em: https://agencia.fiocruz.br/radisaborda-preparo-do-sus-contra-o-novo-coronavirus Acessado em: 21/09/2020.

BICALHO, Aline. 2003. Responsabilidade Social das Empresas: Contribuição das Universidades. São Paulo, Peirópolis, 2003. p. 364.

BRASIL. Constituição da República Federativa do Brasil de 1988. Disponível em: http://www.planalto.gov.br/ccivil_03/constituicao/constituicaocompilado.htm Acessado em: $15 / 09 / 2020$.

BRASIL. Decreto-Lei no 5.452 de $1^{\circ}$ de maio de 1943. Consolidação das Leis Trabalhistas. Disponível em: http://www.planalto.gov.br/ccivil_03/decreto-lei/del5452.htm Acessado em: 18/09/2020.

BRASIL. Medida provisória n. 936. $1^{\circ}$ abril.2020. Institui o Programa Emergencial de Manutenção do Emprego e da Renda e dispõe sobre medidas trabalhistas complementares para enfrentamento do estado de calamidade pública reconhecido pelo Decreto Legislativo $\mathrm{n}^{\circ}$ 6, de 20 de março de 2020, e da emergência de saúde pública de importância internacional decorrente do coronavírus (covid-19), de que trata a Lei $\mathrm{n}^{\circ} 13.979$, de 6 de fevereiro de 2020, e dá outras providências. Disponível em: http://www.planalto.gov.br/ccivil_03/_ato20192022/2020/mpv/mpv936.htm Acessado em: 12/09/2020.

BRITTO, Carlos Ayres. Teoria da constituição. Rio de Janeiro, Forense.2003. p. 216-217.

CARDOSO, Carlos Cabral. Ética e Responsabilidade Social. Comportamento Organizacional e Gestão 21 temas e debates para o século XXI. Lisboa/Portugal. 2002.

CONJUR. Juiz ordena reintegração de funcionários demitidos com base no fato do príncipe. Disponível em https://www.conjur.com.br/dl/juiz-ordena-reintegracao-funcionarios.pdf 
Acessado em: 18/09/2020.

CONSULTOR JURÍDICO. Fato do príncipe não deve prosperar como argumento para governo pagar indenizações. Publicado em 24 de maio de 2020. Disponível em: https://www.conjur.com.br/2020-mai-23/fato-principe-nao-prosperar-argumento-justicatrabalho Acessado em: 22/09/2020.

CORREIO DO POVO. Impacto da Covid-19 na economia aumenta e países amenizam confinamento. Publicado em 08/05/2020. Disponível em: https://www.correiodopovo.com.br/not\%C3\%ADcias/economia/impacto-da-covid-19-naeconomia-aumenta-e-pa\%C3\%ADses-amenizam-confinamento-1.419596 Acessado em 21/09/2020.

DIÁRIO DO RIO. Parmê demite funcionários e diz que governo pagará verbas rescisórias. Publicado em 30/05/2020. Disponível em https://diariodorio.com/parme-demite-funcionariose-diz-que-governo-pagara-verbas-rescisorias/ Acessado em 18/09/2020.

DIÁRIO DO RIO. Fogo de Chão demite 690 e manda a conta para Governadores pagarem. Publicado em 14/05/2020. Disponível em: https://diariodorio.com/fogo-de-chao-demite-690e-manda-a-conta-para-governadores-pagarem/ Acessado em 21/09/2020.

CNN Brasil. Mais de 600 mil pequenas empresas fecharam as portas com coronavírus. Disponível em: https:/www.cnnbrasil.com.br/business/2020/04/09/mais-de-600-milpequenas-empresas-fecharam-as-portas-com-coronavirus Acessado em: 17/09/2020.

ESTADÃO. Publicado em 24/05/2020. Disponível em:https://saude.estadao.com.br/noticias/geral,brasil-tem-653-mortes-e-15-mil-novos-casosde-coronavirus-em-24-horas,70003313138 Acessado em: 24/05/2020.

ESTADÃO. Disponível em: https://brasil.estadao.com.br/ao-vivo/coronavirus-no-brasil Acessado em: 21/09/2020.

FIA - Fundação Instituto de Administração. Responsabilidade Social: O Que É, Importância E Exemplos. Publicado em 29/08/2019. Disponível em:Https://Fia.Com.Br/Blog/Responsabilidade-Social/ Acessado em: 21/09/2020.

FOLHA DE SÃO PAULO. Mais de 1,2 milhão de trabalhadores ficam desempregados no $1^{\circ}$ trimestre. Disponível em: https://www1.folha.uol.com.br/mercado/2020/04/desemprego-vaia-122-com-avanco-do-novo-coronavirus.shtml Acessado em: 21/09/2020.

FOLHA UOL. Fogo de Chão volta atrás e decide pagar rescisão de demitidos. Disponível em: https://www1.folha.uol.com.br/mercado/2020/05/fogo-de-chao-volta-atras-e-decide-pagarrescisao-de-demitidos.shtml Acessado em: 22/09/2020.

GUIMARÃES, Ricardo Pereira de Freitas. Manual de direito individual do trabalho. São Paulo, Revista dos Tribunais. 2014. p. 95-97.

FGV - SB. Sistema de Bibliotecas. GV Executivo. Entrevista Oded Grajew. Disponível em: http://bibliotecadigital.fgv.br/ojs/index.php/gvexecutivo/article/view/34544 Acessado em: 21/09/2020.

INSTITUTO REAÇÃO. 5 Ideias de Responsabilidade Social para Empresas - Publicado em 
31/07/2019. Disponível em: http://www.institutoreacao.org.br/5-ideias-de-responsabilidadesocial-para-empresas/?utm_souce=google\&utm_medium $=$ cpc\&utm_campaign=pd05-trafegoartigos-blog\&gclid=CjwKCAjwh472BRAGEiwAvHVfGp3zdrrNYFgywy8JcFFCH6Qqr9GQjUE15JSAUd_wemDZfBhEjRSfhoCZeEQAvD_BwE Acessado em: $15 / 09 / 2020$.

JUSTIFICANDO. Mentes Abertas Pensam Direito. O Renascimento do Príncipe? Disponível em: https://www.justificando.com/2020/07/24/o-renascimento-do-principe/ Acessado em: 22/09/2020.

LIVRO VERDE - 2001 - Promover um quadro europeu para a responsabilidade social das empresas. Disponível em: https://eur-lex.europa.eu/legalcontent/PT/TXT/HTML/?uri=CELEX:52001DC0366\&from=SV Acessado em: 21/09/2020.

MIGALHAS. Aplicação do "Fato do Príncipe" e o coronavírus. Publicado em 01/04/2020. Disponível em: https://www.migalhas.com.br/depeso/323245/aplicacao-do-fato-do-principee-o-coronavirus Acessado em: 19/09/2020

MORAES, Alexandre de. Direito Constitucional. 25ª Ed. São Paulo, Atlas. 2010. p.197.

NASCIMENTO, Amauri Mascaro. Direito do Trabalho na Constituição de 1988. São Paulo, Saraiva, 1989. p.34.

NUSDEO, Fábio. Curso de Economia. Introdução ao direito econômico. $9^{a}$ ed-ebook. São Paulo, Revista dos Tribunais, 2015.p.221,455 e 460.

OPAS. Folha informativa - COVID-19 (doença causada pelo novo coronavírus) - Atualizada em 18 de setembro de 2020 Disponível em:

https://www.paho.org/bra/index.php?option $=$ com_content\&view $=$ article\&id=6101:covid19\&I temid=875 Acessado em: 21/09/2020.

OPAS. OMS declara emergência de saúde pública de importância internacional por surto de novo coronavírus. Publicado em 30/01/2020. Disponível em:

https://www.paho.org/bra/index.php?option $=$ com_content\&view $=$ article \&id=6100:omsdeclara-emergencia-de-saude-publica-de-importancia-internacional-em-relacao-a-novocoronavirus\&Itemid=812 Acessado em: 16/09/2020.

ORBALENYA, A.E. LAUBER, C; SIDDELL, S. Taxonomy of Viruses: Classification and Nomenclature of viruses. In: Elsevier Reference Collection, 2019. Disponível em: https://www.sciencedirect.com/science/article/pii/B9780128012383992377?via\%3Dihub Acessado em: 21/09/2020.

PACTO GLOBAL REDE BRASIL Pacto contra a COVID-19. Disponível em: https://www.pactoglobal.org.br/pg/pacto-contra-covid-19 Acessado em: 21/09/2020.

ROCKCONTENT. A Responsabilidade Social Empresarial é uma política que guia todos os passos da empresa, de forma a torná-la mais ética, responsável, sustentável e humana. A RSE influencia na condução do negócio e como a empresa lida com os parceiros, colaboradores e clientes. Publicado em 10/09/2019. Disponível em:

https://rockcontent.com/blog/responsabilidade-social-empresarial/ Acessado em: 21/09/2020.

RUSSOMANO, Mozart Victor. Consolidação das leis trabalhistas anotada. 5. ed. Rio de 
Janeiro. Ed.Forense, 2003.

SILVA, Lima Fabrício. PINHEIRO, Iuri. Manual do Compliance Trabalhista. Teoria e Prática. Ed. JusPODVM. 2020. p.39.

TAVARES, André Barros. Direito Constitucional da Empresa. São Paulo, Método, 2013. p.93.

TJDFT. Parceria entre VIJ/DF e IEDF resgata o princípio da fraternidade para beneficiar crianças e adolescentes do DF. Disponível em: https://www.tjdft.jus.br/informacoes/infanciae-juventude/noticias-e-destaques/2017/agosto/parceria-entre-vij-df-e-iedf-resgata-o-principioda-fraternidade-para-beneficiar-criancas-e-adolescentes-do-df Acessado em: 20/08/2020

UOL. Aulas suspensas e home office: como estados e municípios atuam em pandemia. Publicado em 18/03/2020. Disponível em: https://noticias.uol.com.br/saude/ultimasnoticias/redacao/2020/03/14/confira-medidas-adotadas-por-estados-e-municipios-nocombate-ao-coronavirus.htm Acessado em: 21/09/2020.

UOL. Quarentena em São Paulo e no Rio: O que você pode e o que não pode fazer. Publicado em 25/03/2020. Disponível em: https://noticias.uol.com.br/saude/ultimasnoticias/redacao/2020/03/25/quarentena-em-sao-paulo-o-que-voce-pode-e-o-que-nao-podefazer.htm Acessado em 21/09/2020.

VARGAS, Camila Beatriz de. Sustentabilidade e Consumo Consciente: A Percepção da Evolução do Modo de Consumir e como isso Pode Afetar a Gestão nos Próximos Anos. Disponível em:

http://www.ucs.br/etc/conferencias/index.php/mostraucsppga/xvmostrappga/paper/viewFile/4 187/1371 Acessado em: 14/09/2020. 